\title{
Health Information Technology Problems in Universiti Teknologi Malaysia's Clinic
}

\author{
MaralCheperli ${ }^{1}$, MalahatPouran Safar ${ }^{1}$, SyaAzmeelaShariff ${ }^{1}$, \\ Mohammad Reza Faraj Tabrizi ${ }^{2}$ \\ ${ }^{1}$ UNIVERSITI TEKNOLOGI MALAYSIA, Advance Informatics School (AIS), \\ ${ }^{2}$ UNIVERSITI TEKNOLOGI MALAYSIA, International Business School (IBS)
}

\begin{abstract}
By significant improvement in technology, Health Information Technology (HIT) should be ata higher level of quality and safer care to be more responsive to patients' demands. The major benefits of HIT are cost reducing, quality improving, and better patient experience. In this article, we explain HIT system which is used by The Universiti Teknologi Malaysia's clinic and problems they have. To find out the problems of HIT, the interview is conducted with the stakeholders of the system that included clinic staff and doctors. The findings of this research have lessons for improving the clinic's system and future researches.
\end{abstract}

Keywords: Health Information Technology; stakeholders; cost; quality; patient.

\section{Introduction}

Health Information Technology (HIT) is the information processed application which involves both computer software and hardware to store, retrieve, share, and use of health care information, data, and knowledge for communication and making decisions (Lluch, 2011). In the other words, Health information technology (HIT) is the area of IT that involves the design, development, creation, use and maintenance of information systems for the healthcare industry (Behkami\& U. Dame, 2012). Automated and interoperable healthcare information systems are expected to lower costs, improve efficiency and reduce error, and also providing better consumer care and service (Rouse, 2010). By improving communication and sharing information, HIT is considered as a critical tool for improving the safety and quality in care transitions, and numerous stakeholders recognize it as a right tool for improving quality and outcomes (patient and family experience) of care, care disparity redaction("Improving Transitions of Care with Health Information Technology," 2010).

Healthcare systems use HIT to provide services that are efficient, cost effective, quality, and safe for everyone. One of the major uses of HIT is to reduce medical errors, for example, Gundersen Lutheran's health information technology network connects more than 70 healthcare facilities in predominantly rural areas across Wisconsin, Minnesota and Iowa. The health IT network supports Gundersen Lutheran's ability to provide a higher level of care for patients in a more coordinated and timely manner and also reducing the chance for medical errors . There are some definitions about HIT in healthcare system which is listed at below table:

Table 1: Records Terms (Bell, 2008)

\begin{tabular}{|c|c|c|}
\hline Electronic Medical Record & Electronic Health Record & Personal Health Record \\
\hline $\begin{array}{c}\text { An electronic record of } \\
\text { information which is related to } \\
\text { health and clinicians and staff } \\
\text { in a health care organization } \\
\text { can create, gather, manage, and } \\
\text { consult about it. }\end{array}$ & $\begin{array}{c}\text { An electronic record of } \\
\text { information which is related to } \\
\text { health and it is according to the } \\
\text { international standards and } \\
\text { clinicians and staff in more than } \\
\text { one health care organization can } \\
\text { create, gather, manage, and } \\
\text { consult about it. }\end{array}$ & $\begin{array}{c}\text { An electronic record } \\
\text { information which is related to } \\
\text { health and it is according to the } \\
\text { international standards and } \\
\text { individual can manage, share, } \\
\text { and control it. It can be created } \\
\text { from various sources. }\end{array}$ \\
\hline
\end{tabular}

Table 2: Network Terms(Bell, 2008)

\begin{tabular}{|c|c|c|}
\hline Health Information Exchange & Health Information Organization & $\begin{array}{c}\text { Regional Health Information } \\
\text { Organization }\end{array}$ \\
\hline $\begin{array}{c}\text { Electronically transferring the } \\
\text { health information through an } \\
\text { organization based on the } \\
\text { international standards. }\end{array}$ & $\begin{array}{c}\text { An organization that control and } \\
\text { monitor the exchange of the health } \\
\text { information among organizations } \\
\text { based on the international standards. }\end{array}$ & $\begin{array}{c}\text { A health information organization } \\
\text { that to improve health and care, } \\
\text { gather stakeholders of health care in } \\
\text { a specific geographic area and } \\
\text { monitor health information } \\
\text { exchange among them. }\end{array}$ \\
\hline
\end{tabular}


Today, there are enormous ranges of applications of HIT in thee health care organizationalsystemm (for example Cernerisann electronic medical recordsystemm, ProSolvCardioVascular for medical imaging) (Behkami\& U. Daim, 2012). The technology has been improved significantly and HIT implementation is expected to be in higher quality and safer care that is more responsive to patients' needs and also more efficient (Kern \& Kaushal, 2007). HIT is associated with cost reducing, quality improving, and better patient experience, but HIT is difficult to implement (Pannarunothai, \&Speedie, 2009). Although computers are used increasingly in hospitals and practices, not all healthcare professionals use HIT (Rippen, Pan, Russell, Byrne, \& Swift). Knowledge about the changes in organization, costs, and time is required for healthcare centers to successfully implement systems (Lluch, 2011).

The purpose of this study is identifying problems of HIT systems and alsoa current HIT system which is used at International campus of Universiti Teknologi Malaysia's clinic in Kuala Lumpur, and proposes some suggestions to help solve those problems. To identify the problems of HIT, the interview is conducted with the stakeholders of the system that included clinic staff and doctors.

\section{Problem Introduction}

Information has an important role in health care. Information isgenerated and processed in hospitals or clinics or other health organizations as they provide care to patients. Complexity of the health care system, having a lot of different kinds of providers and services, make if difficult and challenging to manage and control the information to us(Devon M. Herrick \& 2010).

Health IT refers to computer applications that are related to medicine.These applications may use for computerized ordering of medications or any kind of test, supporting system for making decisions in clinics, and medication prescription electronically(Behkami \& U. Daim, 2012).

This study will identify some problems of HIT systems and then will explain about some problems of the UTM clinic. As it mentioned before, HIT has a lot of advantages like cost effectiveness, patient safety and the other benefits. But besides of a lot of advantages, it causes to have other kinds of problems. In this study we want to explain about some of these problems.

\subsection{HIT Causes New Errors}

HIT systems try to help health care organizations to prevent common mistakes and errors, but these systems also introduce new errors. One of the articles in the Journal of the American Medical Association mentioned that using the HIT system will "foster errors rather than reduce their likelihood (Joan, 2004).

2.1.1 Error of Order Entry system: These systems are easy to learn and they have been adopted rapidly by hospitals and clinics. They have been significantly reduced medication errors and incompatible drug events. But recent studies point about the impact of the new errors, like selecting the wrong drug on drop down list mistakenly. Also if the electronic system fails, how critical medications will be accessed (Reckmann, 2009). By making order entry system computerized, errors of medication prescription reduced; however, these facilities didn't prove in pediatric or ICU (Rosse, 2009).

2.1.2 Data Overloading Problem: Another problem is about data and makes information overloading and if the time needed for entering data reduces from patient care. Studies show that even in the health system, with long time of using electronic systems, pen and paper workarounds are used (Rosse, 2009). One reason for using paper is that communication via paper lead to improve efficiency and better data organization. The problem is the system that has been used for recording the patient medications and treatments, so this information is not same as the information for billing, or operation controls (Rosse, 2009).

Another problem of implementing HIT is variety, complexity and time dependence of clinic workflow (Reckmann, 2009). Sometimes physicians need to make decisions rapidly and maybe with uncertainty. Others need precise planning and study. It means that staffs sometimes have to do routine things which are not necessary but cost effective. For example, one patient needs to register for a routine vision exam and the other one needs to register for cancer surgery with complex details. Using one HIT system for all health care organizations is the wrong way because the information requirement can be different from time to time in a same clinic (Rosse, 2009).It is a usual event in hospitals that sometimes move to high occupancy from normal and require for making extremely rapid decision about bed allocation, starting surgical procedure and the other actions. To resource allocation suddenly, staff should know a lot of information about what will be happening at any time and may be these informationmay not be availablewithy a HIT system designed for normal operations. 


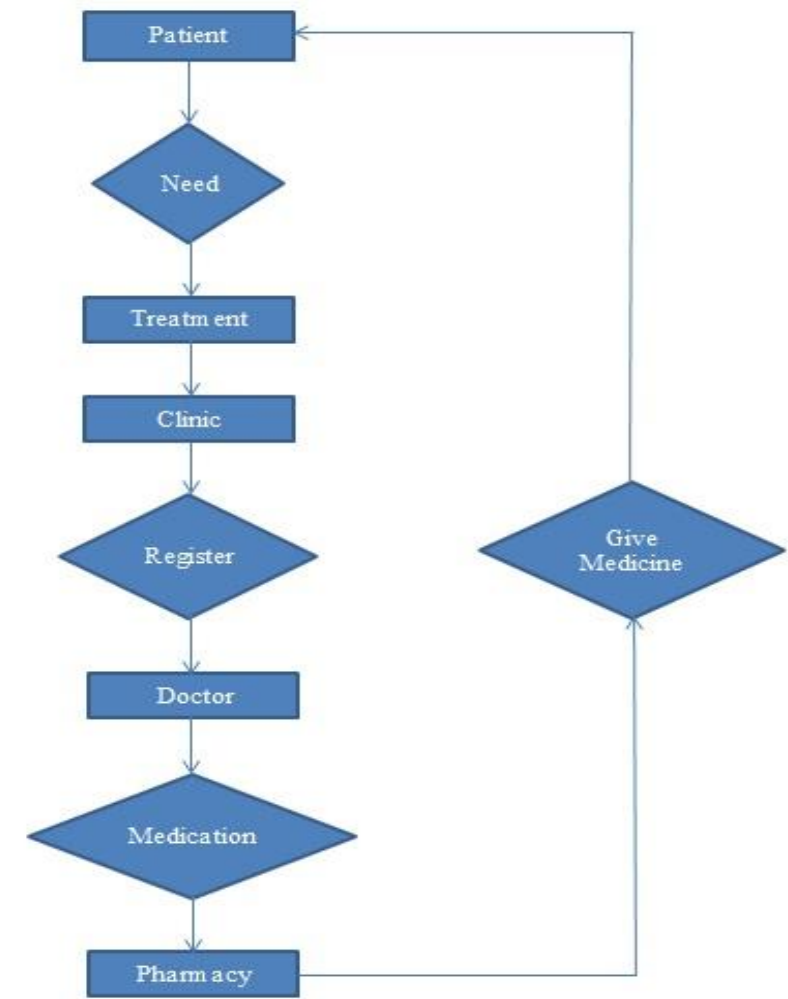

Figure 1. Stages from patients to get medication in UTM clinic

This study also will identify the major problems of the HIT system which is used inthe clinicin Universiti Teknologi Malaysia, International Campus, in Kuala Lumpur. The clinic is using the system since 1997 and, from that time till now, they are updating and maintaining the system every year. All the staffs in the clinic (10 persons) are users of the system and each user can open different system. The HIT system in this clinic plays a key roleinstoring data ofeach patient whether the patient comes again, staff can see all the data without needs to register again. This system uses the matrix cart of each student or staff to identify the patient. And the other usage of the system is consultation from the doctors' room and link to pharmacy staff who gives the medication to the patients. Sending the list of medicines from the doctor's room directly to the pharmacy lead to prevent paper working and also help to save time.

By conducting interviews with the clinic's staff, we identify major problems that they have with the system. One of the most important problems that they have is about the database of the system and updating it. They update the system without checking the list of current students of the UTM. They do not do this and so they cannot identify if the student is graduated or not to stop giving free medication.

The other problem is about linking the UTM clinic in Johor Bahru, main campus, with the Kuala Lumpur campus. If a student of the Johor Bahru campus goes to the Kuala Lumpur campus clinic and get medication, clinic staff cannot receive the data of the student from the Johor Bahru clinic and vice versa.

In this study, we want to propose some solutions to the first mentioned problem and help to the UTM's clinic about updatingtheir system.

\subsection{Database and Its Objectives}

A database collects and organizes the related data so extracting that useful data becomes easy. In health care system, the database can be used for patient care recording, patient status monitoring, and treatment advising(Wiederhold, 1979). Researchers can use it to assess the effectiveness of medicines and procedures of clinical. Also database can be used for accounting cost and making decisions about service facilities by management (Wiederhold, 1979).

Sharing data increases information consistency for making decision and help to decrease repetitive data collection. A main benefit of using database in health care is providing the information of services for management to making decisions about the allocation of resources which is needed for those services (Wiederhold, 1979). Also by sharing information among health care providers, their communications will be spread and this can lead to validate the medical care hypotheses by patient observation (Wiederhold, 1979).

The database of UTM clinic has two major scopes:

1. Patient Information 
2. Staff Information

Some of the fields of each scope are:

$\begin{array}{ll}\text { - } & \text { Patient Information } \\ \text { - } & \text { Name } \\ \text { - } & \text { Sex } \\ & \text { Occupation } \\ & \text { - Student } \\ \text { - } & \text { Address Staff } \\ - & \text { Phone Number } \\ \text { - } & \text { Date }\end{array}$

$\begin{array}{ll}\text { - Staff Information } \\ \text { - } & \text { Staff Name } \\ \text { - } & \text { Staff ID } \\ \text { - } & \text { Date of Birth } \\ \text { - } & \text { IC Number } \\ \text { - } & \text { Address } \\ \text { - } & \text { Experience } \\ \text { - } & \text { Starting date } \\ \text { - } & \text { Sex } \\ \text { - } & \text { Salary } \\ \text { - } & \text { Occupation }\end{array}$

\section{Methodology}

The main purpose of this study is determining the problems of HIT systems. This study was conducted at the clinic of Universiti Teknologi Malaysia, International Campus, in Kuala Lumpur. This study was used qualitative research methodology. The instrument which is used for this study was interviewed to collect substantive and relevant data.

To find out the problems of the HIT system at this clinic, interviews were done by staff about that. Questions of the interview were about functionalities and features of the system and clinic's needs that this system cannot provide for them.

\section{Results}

As mentioned before, the important problem of the HIT systemat the UTM clinic is about updating the database of the system. The current system cannot identify if the student is graduated or not. The clinic staff or software technicians should update their system more than once a year based on the list of current students. Without checking the graduated students list, the clinic should spend more money for inventories and coverthe overhead costs of freemedications for non-student persons. This solution leads to stop to give free medication to persons that are not students anymore at UTM.

We found out that there is just one IT person to maintain and update the system. Also this person comes from Johor Bahru, and he is not accessible at any time. He comes once a year to repair and update the system.So, lack of system professions is the other problem of the current system. The system needs more than one technician at each campus of UTM (Johor Bahru and Kuala Lumpur) to monitor, control, update, and maintain the system. Having more IT persons to check and control the system will leads to have more applicable and efficient system.

\section{Conclusion}

The medicineis becoming more and more complex and it becomes more complicated to provide the right care to patients without support of modern health information technology. Development in diagnosis and treatment like prescription, devices, and procedures help to improve patient health outcomes and quality of life. For example, advances in HIT make it easier to prescribe and refill medications, order and receive results of laboratory and imaging tests, and obtain information from specialists and hospitals on care patients have received outside a primary care practice.

HIT has a lot of advantages and benefits that the most important of them are: improvingqualitycost reducing, and better patient experience. Clinical HIT systems may affect significantly on medical quality and safety by using automated decision making and knowledge tools within the medical provider. Thus, errors of 
omission that are caused by gaps in knowledge provider or the failure to integrate and apply that knowledge in clinical practice will be decreased.

This study wasan attempt to identify some major problems of the HIT system atthe UTM clinic in the Kuala Lumpur campus and propose some suggestion to solve them. One of these problems is in database section and updating it according to the current students of the university. The other one is about the lack of IT professionals to check and monitor and updating it. This study was provided some suggestion to solve them.

This study was found problems and proposed some suggestion from the perspective of clinic staff. Further studies are needed to identify the problems and expectations from the perspective of students and also about functionalities and features of the system. Future studies can search about the functionalities which staffs need them, but it is not available from the current system.

\section{Acknowledgement}

The authors of this paper are grateful to Dr. AbdolrashidCheperli and Dr. Benyamin Davaji for their support and comments on this paper. Furthermore, the authors would like to cordially appreciate the esteemed respondents of the study.

\section{References:}

[1] Behkami, N. A., \& U. Daim, T. (2012). Research Forecasting for Health Information Technology (HIT), using technology intelligently. Technological Forecasting and Social Change, 79 (3), 498-508.

[2] Bell, K. M. (2008). Defining Key Health Information Technology Terms Available from http://healthit.hhs.gov/portal/server.pt/gateway/PTARGS_0_10741_848133_0_0_18/10_2_hit_terms.pdf

[3] Devon M. Herrick, L. G., \& , J. C. G. (2010). Health Information Technology: Benefits and Problems Available from http://www.ncpa.org/pdfs/st327.pdf

[4] F. van Rosse et al.(2009). The Effect of Computerized Physician Order Entry on Medication Prescription Errors and Clinical Outcome in Pediatric and Intensive Care: A Systematic Review.Pediatrics, 123 (4), 1184-90.

[5] Improving Transitions of Care with Health Information Technology. (2010). Available from http://www.ntocc.org/Portals/0/PDF/Resources/HITPaper.pdf

[6] Joan S.Ash et al.(2004). Computerized Physician Order Entry Systems in U.S. Hospitals: Results of a 2002 Survey. Journal of the American Medical Informatics Association, 11 (2), 95-9.

[7] Kern, L. M., \& Kaushal, R. (2007). Health information technology and health information exchange in New York State: New initiatives in implementation and evaluation. Journal of Biomedical Informatics, 40 (6, Supplement), S17-S20.

[8] Kijsanayotin, B., Pannarunothai, S., \& Speedie, S. M. (2009). Factors influencing health information technology adoption in Thailand's community health centers: Applying the UTAUT model. International Journal of Medical Informatics, 78 (6), 404-416.

[9] Lluch, M. (2011). Healthcare professionals' organizational barriers to health information technologies-A literature review. International Journal of Medical Informatics, 80 (12), 849-862.

[10] M.H. Reckmann et al.(2009). Coes Computerized Provider Order Entry Reduce Prescribing Errors fo Hospital Inpatients? A Systematic Revies.Journal of the American Medical Informatics, 16 (5), 613-23.

[11] R. Orszag, P. (2008). Evidence on the Costs and Benefits of Health Information Technology Available from http://www.cbo.gov/sites/default/files/cbofiles/ftpdocs/91xx/doc9168/05-20-healthit.pdf

[12] Rippen, H. E., Pan, E. C., Russell, C., Byrne, C. M., \& Swift, E. K. Organizational framework for health information technology. International Journal of Medical Informatics (0).

[13] Wiederhold, G. (1979). DATABASES IN HEALTHCARE Available from ftp://171.64.75.201/pub/cstr/reports/cs/tr/80/790/CS-TR80-790.pdf 